University of Nebraska - Lincoln

DigitalCommons@University of Nebraska - Lincoln

September 1975

\title{
Technique for rapid Faraday susceptibility measurements
}

\author{
F.R. Szofran \\ University of Nebraska - Lincoln \\ W.L. Burmester \\ University of Nebraska - Lincoln \\ David J. Sellmyer \\ University of Nebraska-Lincoln, dsellmyer@unl.edu \\ L.G. Rubin \\ Francis Bitter National Magnet Laboratory, Massachusetts Institute of Technology, Cambridge, \\ Massachusetts
}

Follow this and additional works at: https://digitalcommons.unl.edu/physicssellmyer

Part of the Physics Commons

Szofran, F.R.; Burmester, W.L.; Sellmyer, David J.; and Rubin, L.G., "Technique for rapid Faraday susceptibility measurements" (1975). David Sellmyer Publications. 187.

https://digitalcommons.unl.edu/physicssellmyer/187

This Article is brought to you for free and open access by the Research Papers in Physics and Astronomy at DigitalCommons@University of Nebraska - Lincoln. It has been accepted for inclusion in David Sellmyer Publications by an authorized administrator of DigitalCommons@University of Nebraska - Lincoln. 


\title{
Technique for rapid Faraday susceptibility measurements*
}

\author{
F. R. Szofran, † W. L. Burmester, and D. J. Sellmyer \\ Behlen Laboratory of Physics, University of Nebraska, Lincoln, Nebraska 68508
}

L. G. Rubin

Francis Bitter National Magnet Laboratory, Massachusetts Institute of Technology, Cambridge, Massachusetts 02139

(Received 18 April 1975; in final form 6 June 1975)

An apparatus is described which permits the rapid acquisition and computer analysis of temperature-dependent Faraday susceptibility data. The apparatus utilizes a relatively inexpensive, three-channel, data-acquisition system.

In recent years, a number of Faraday susceptibility systems have been described in the literature. ${ }^{1-7}$ These systems typically use an electrobalance to measure the change in force on a sample hanging in an inhomogeneous magnetic field, as the field or field gradient is turned on and off. There are various noise and drift problems associated with such measurements which make it somewhat difficult to couple these experiments to automated, digital data acquisition systems. Therefore, Faraday results generally have been obtained by manually measuring voltage differences from strip-chart recorders, for example. Acquisition and analysis of data from this type of experiment can be fairly tedious. For these reasons, we have developed a Faraday system coupled with an automated, digital data acquisition system. This apparatus has enabled us to obtain data rapidly and determine constants such as effective moments and Weiss temperatures from Curie-Weiss fits. In this note we present a description of our system.

Basically, the Faraday apparatus consists of a Cahn RG electrobalance, a Varian $10-\mathrm{cm}$ magnet, and a Janis VariTemp Dewar capable of measurements between 1.3 and $300 \mathrm{~K}$. The design in general is similar to that of Dellby and Ekström. ${ }^{5}$

The data acquisition system consists of three digital voltmeter (DVMs) with binary-coded decimal (BCD) outputs

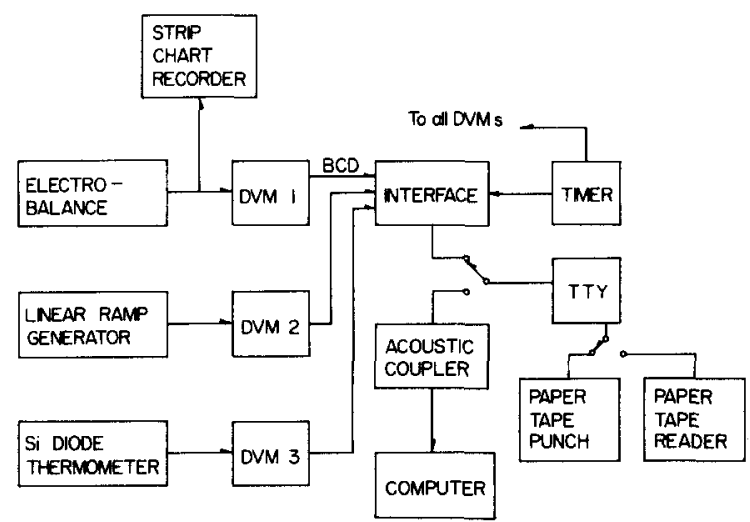

FIG. 1. Block diagram of data acquisition system as it is configured for recording Faraday susceptibility data. Some of the components are as follows: Thermometer-Lakeshore Cryotronics model DT-500; ramp generator-Hewlett-Packard model 3310A; DVM 1-Keithley model 180; DVM 2-Fluke model 8100B; DVM 3-Newport model 2000AS-2; interface-Data Graphics, Datos 305; timer-a home-made circuit using an EXAR model XR320 integrated circuit; TTY-model ASR-33; coupler-Livermore Data Systems model B. which are recorded on Teletype (TTY) paper tape. The data are subsequently read into a computer via a telephone line using the TTY and an acoustic coupler. A block diagram of the data acquisition system is shown in Fig. 1.

Except for one difficulty, to be mentioned below, data could be taken simply by turning the magnetic field on and off a number of times and then determining the difference between the field-off and field-on electrobalance signals. The electrobalance can be adjusted so that its output changes sign whenever the field is turned on or off. This enables the data analysis program to distinguish field-on from field-off data, since sign information is included.

The problem alluded to above is that we have occasionally experienced a slow drift of the electrobalance output which changes linearly in time over periods ranging up to several hours. Thus, the output signal, as a function of time and as the field is turned on and off, appears to be a skewed square wave as shown in Fig. 2. Under these circumstances, it follows that one cannot simply average separately field-off and field-on data and take the signal as the difference of these two averages, since the result would depend on the time ranges over which the field-off and field-on data were obtained. We have, therefore, added a linear ramp generator and DVM 2 to the system and written the data analysis program so that it fits (as a function of time) a line $\left(A A^{\prime}\right)$ to all of the field-off data for a given temperature, fits another line $\left(B B^{\prime}\right)$ to the field-on data which are constrained to have the same slope as the field-off data, and then takes

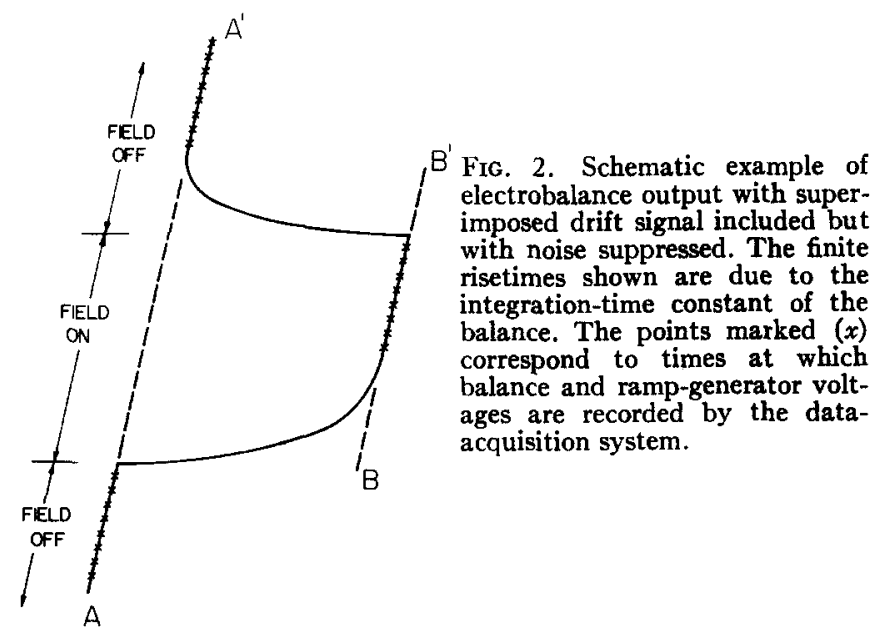


the difference in the constant terms of the two lines as the susceptibility signal for that temperature. Inclusion of the ramp function in the recorded data provides the necessary time-range information and, thus, allows us to wait an arbitrary length of time before beginning to record data after the field is turned on or off.

The timer in Fig. 1 is a home-made integrator that activates the DVMs and interface, and causes data to be punched in intervals adjustable from 2 to $75 \mathrm{sec}$; the interval can be expanded to several minutes if desired. The activation signal from the timer causes all three DVMs to update their output buffers simultaneously, and the interface transmits these sequentially to the output device.

DVM 3 is used to record the temperature in terms of the voltage across a commercially available $\mathrm{Si}$ diode thermometer. ${ }^{8}$ Because of the high source impedance of the diode, it was calibrated with the same DVM used to take data in order to avoid possible loading effects. The data analysis program computes the temperature on the basis of the fieldoff readings only and ignores the field-on readings, which are erroneous because of magnetoresistance. ${ }^{8}$

An example of data taken by means of this system and analyzed and plotted by computer is shown in Fig. $3 .{ }^{9}$ Use of the system is not limited to samples with large susceptibilities such as the one shown. The limit of our mass susceptibility sensitivity is about $5 \times 10^{-10} \mathrm{~cm}^{3} / \mathrm{g}$ at a field of $\sim 10 \mathrm{kOe}$, with sample masses typically in the range 20 $100 \mathrm{mg}$.

In addition to Faraday susceptibility experiments, ${ }^{9,10}$ the system is being used in conjunction with electrical resistance, ${ }^{10}$ vibrating-sample magnetometer, ${ }^{9,10}$ and de Haas-van Alphen experiments.
Fig. 3. Example of susceptibility data $\chi(T)$ on an Fe-chain silicate compound with an antiferromagnetic transition at 31.5 K (see Ref. 9). The field value was $3.2 \mathrm{kOe}$.

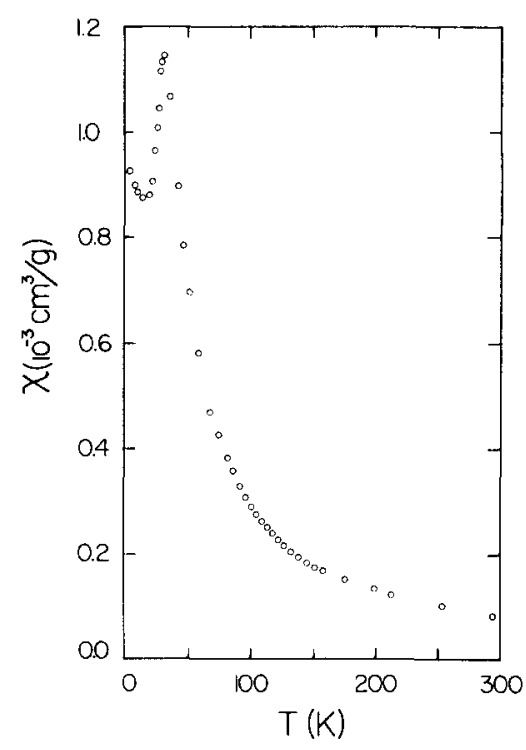

* Research supported by the National Science Foundation.

†Present address: Corporate Research Center, Universal Oil Products Company, Des Plaines, IL 60016.

${ }^{1}$ A. N. Gerritsen and D. H. Damon, Rev. Sci. Instrum. 33, 301 (1962).

${ }^{2} \mathrm{~J}$. T. Richardson and J. O. Beauxis, Rev. Sci. Instrum. 34, 877 (1963).

${ }^{3} \mathrm{C}$. M. Hurd, Cryogenics 6, 264 (1966).

${ }^{4}$ B. L. Morris and A. Wold, Rev. Sci. Instrum. 38, 1937 (1968).

${ }^{5}$ B. Dellby and H. E. Ekström, J. Phys. E 5, 342 (1971).

${ }^{6}$ R. T. Lewis, Rev. Sci. Instrum. 42, 31 (1971).

${ }^{7}$ R. K. Quinn and R. C. Knauer, Rev. Sci. Instrum. 43, 1543 (1972).

${ }^{8}$ Lakeshore Cryotronics, Eden, NY 14057. Data Sheet LB 1172-1.

${ }^{\circ}$ R. J. Borg, F. R. Szofran, W. L. Burmester, and D. J. Sellmyer, AIP Conf. Proc. No. 24,365 (1975).

${ }^{10}$ F. R. Szofran, J. W. Weymouth, G. R. Gruzalski, D. J. Sellmyer R. Ray, and B. C. Giessen, AIP Conf. Proc. No. 18, 284 (1974); and Bull. Am. Phys. Soc. 19, 253 (1974). 